\title{
Unleashing the Potential and Pitfalls of the iPad on Undergraduate Nursing Students in Tertiary Education
}

\author{
Christine Minty-Walker \\ Nathan J. Wilson \\ Lucie Ramjan \\ Paul Glew \\ School of Nursing and Midwifery \\ Western Sydney University
}

\begin{abstract}
The proliferation in the use of technological devices in tertiary education is rapidly evolving. Universities are adopting strategies that provide a more flexible and accessible learning and teaching environment. The introduction of iPads formed part of one large multi-campus Australian University's strategy to engage students learning with a mobile device, yet until now there has been no evaluation or research about this strategy. We used Interpretative Phenomenological Analysis (IPA) to explore the lived experience of undergraduate nursing students when using the iPad. Findings revealed the participants found the iPad supportive in their studies within a blended learning environment. However, this experience was challenged by limitations as the participants adapted to using this Apple brand mobile device. A foundation of training and support was not provided; hence the capabilities of the iPad were not used to its full potential. This research supported current literature, however also illuminated recommendations for future research. The importance of providing a foundation of preliminary support when implementing a mobile device into a tertiary setting is imperative. This research is the first to explore the lived experience of undergraduate nursing students when using the iPad for tertiary education.
\end{abstract}

Keywords: iPad, tertiary education, e-learning, blended learning, nursing students.

\section{Introduction}

Tertiary education is continuing to refine and develop strategies that incorporate existing and emerging technologies to assist students with learning. At the forefront of this technological transformation are mobile devices. The incorporation of mobile devices, such as the Apple iPad, into tertiary education is providing a learning experience that enables ubiquitous learning. That is, the ability for learning to occur anywhere, anytime - factors central to the world of mobile learning (m-learning) (Peng, Su, Chou \&Tsai, 2009). Since the iPad was first released in April 2010 (Nguyen, Barton, \& Nguyen, 2015), it has been one of the largest selling mobile devices (Bansavich \& Yoshioka, 2011). The iPad, along with other mobile devices, enables m-learning which facilitates the acquisition of knowledge without the constraints of fixed place and time (Traxler, 2010). One large multi-campus Australian University was the first tertiary institution to spearhead the roll out of iPads in 2013, with eleven thousand iPads distributed to all new first-year undergraduate students. The University's analysis revealed that over $80 \%$ of logins to the university's e-learning system were from an Apple device, thus the iPad was the University's device of choice. This analysis also revealed that the variety of applications (apps) and programs available would likely benefit student education (University of Western Sydney [UWS], 2015b). The iPad roll out formed part of the university's strategy to engage students with a mobile device that would allow for flexibility and freedom in their studies. It now forms an integral component of the blended learning strategy, integrating face-to-face, online and community-based interactions (UWS, 2015a). This has seen large-scale face-to-face lectures replaced by the opportunity to view lectures online or as a Podcast (UWS, 2015). 


\section{Background}

A review of 17 known research papers about the exclusive use of Apple iPads in tertiary education showed study sample sizes ranged from $<50(n=9), 51-100(n=2)$ and $>100(n=6)$. Predominately, these studies were conducted in the United States of America (USA) $(n=10)$ and Australia $(n=3)$. We thematically categorised these 17 articles as follows: i) impact of iPads on academic engagement; ii) different implementation of strategies and samples; iii) workflow and functionality of the iPad's features and; iv) mobile applications (apps) in learning in learning.

\section{Impact of iPads on academic engagement}

The use of the iPad in student learning was reported in 14 papers. A positive association was found in a USA study, between the use of the iPad and increased academic engagement, motivation and perception of learning (Diemer, Fernandez, \& Streepey, 2012). Learning was reportedly enhanced as the iPad was used as a tool to source content during class discussions. This easy access to information fostered more in-depth discussions, problem solving and a collaborative learning environment. Classes were reported to be fun, interesting and exciting, which increased the motivation of students to learn course content (Rossing, Miller, Cecil, \& Stamper, 2012; Wakefield \& Smith, 2012). Despite these reported benefits, its potential to distract learners and create frustration in the classroom was discussed in two Australian studies (Brown \& McCrorie, 2015; Kinash, Brand, Mathew \& Kordyban, 2011), as students considered the iPad a novelty and distraction to their studies. Conversely, two studies reported that students who focused on accessing educational material in the classroom did not find the iPad a distraction, rather it enhanced the retention of information (Eichenlaub, Gabel, Jakubek, McCarthy, \& Wang, 2011; Klapdor \& Uys, 2013).

\section{Different implementation strategies and samples}

Seventeen studies described and evaluated very different implementations of the iPad initiative. For example, in a small-scale US study, research was based on twelve graduate students who had purchased their own iPad (Alyahya \& Gall, 2012). In contrast, in a large-scale institution-wide initiative in the -United Arab Emirates, 41,000 iPads were distributed to all first year students and staff over a nine-week period in which time structured iPad training sessions occurred. The duration of the iPad initiatives varied widely, ranging from one week (Hahn \& Bussell), to two years (Rossing et al., 2012). The distribution of the iPads involved both staff and students. However, eleven studies involved students exclusively (e.g., Hahn \& Bussell, 2012). The issue regarding iPad ownership and affordability was raised in several studies; in one study 40 iPads were deployed as a shared resource among 217 students (Rossing et al., 2012), and in the study by Kinash et al., (2011) students loaned an iPad for a two-week period. In two other studies the issue of iPad affordability following the iPad study was raised (Eichenlaub et al., 2011; Sloan, 2012). Overall, the variations in sample groups, populations and duration of studies allowed for a diverse range of findings.

\section{Workflow and functionality of the iPad's features}

There were wide variations in the feedback on the workflow and functionality of the iPads' features. Reportedly, the most important feature of the iPad was its portability (Alyahya \& Gall, 2012; Eichenlaub et al., 2011; Hahn \& Bussell, 2012; Kinash et al., 2011; Smith, Kukulska-Hulme \& Page, 2012). Students commended the lightweight design, excellent battery life, quick start up and intuitive touch screen interface as superior compared to a laptop (Eichenlaub et al., 2011). Students also reported preferring the iPad over their laptop when it came to annotating and reading documents making for a more paper-free learning environment. Furthermore, the participants found it was easier to bring an iPad to class than a laptop (Hahn \& Bussell, 2012) in relation to its size (Eichenlaub et al., 2011). However, some students preferred a laptop or computer for assignments 
(Alyahya \& Gall, 2012; Klapdor \& Uys, 2013). In contrast, the limitations of the iPad were noted including the absence of Flash (Culen \& Gasparini, 2011); Universal Serial Bus (USB) output (Eichenlaub et al., 2011); printing functions; and the appropriate size of the touch-screen keyboard (Rossing et al., 2012).

\section{Mobile applications in learning}

Learning and teaching was assisted through the use of apps available on the iPad. A regional planning undergraduate student used the iBrainstorm app to copy diagrams, then typed notes onto the Pages app, finding their learning was aided by the iPad's organisation of academic notes (Eichenlaub et al., 2011). In contrast, some students found taking notes on the iPad difficult, as the application iAnnotate was difficult to master and that two apps could not be opened at once (Eichenlaub et al., 2011). Further concerns were noted in a Norwegian study where students claimed it was time consuming to learn how to use new apps as the emphasis was on obtaining good grades, not exploring the app possibilities (Culén \& Gasparini, 2011), highlighting the need to guide students on the use of apps relevant to their learning needs.

To summarise, the iPad's use in tertiary education appears to have benefits and limitations within a technologically advanced classroom. Missing from the literature were any studies that reported on the lived experience of nursing students when using the iPad for tertiary education. This study sought to fill this gap by exploring nursing students' perspectives on the lived experience of using the iPad for their tertiary study.

\section{Methodology}

To capture the students' lived experience Interpretative Phenomenological Analysis (IPA) was selected as the aim of IPA is to make sense of the reality of the participants' lifeworld (Smith \& Osborn, 2008). Understanding this reality requires the researcher to describe and interpret the essence of the lived experience for the individual (Polit \& Beck, 2006). Individual interviews were conducted with undergraduate nursing students between March and June, 2015. A semi-structured interview schedule focused on the following topics: the use of the iPad in the academic environment; the integration of the iPad into a blended learning environment; and the positive and negative features of the iPad to assist learning. Ethical approval was granted from the Western Sydney University Human Research Ethics Committee (Approval ID: H10902) and all participants provided written informed consent.

\section{Participants}

To generate information rich cases, participants $(n=9)$ were recruited using a purposive sampling method as participants "have firsthand experience with the phenomenon under investigation" (Gillis \& Jackson, 2002, p. 184). In accordance with IPA, the sample is typically homogeneous due to the small sample size, allowing for the understanding of a particular group, not the generalisations of a wider population (Smith \& Osborn, 2008). In this case, nursing students with the direct experience of using an iPad for learning were recruited from one campus of the university. The recruitment process involved placing a general advertisement for second year nursing students on the university's e-learning platform. Inclusion criteria were: 1) second year undergraduate Bachelor of Nursing student; 2) received a complementary iPad from the university 12 months prior to the study; 3) aged 18 years or over; and 4) based at one campus of the university. Exclusion criteria were: 1) any student currently being taught by the interviewer. As the interviewer was in a position of authority, care was taken not to entice student participation and a neutral interview location was selected for the interviews. Participant demographic data are summarised in Table 1. 
Table 1: Participant Demographic Data

\begin{tabular}{|c|c|}
\hline \multicolumn{2}{|l|}{ Participants $\mathrm{N}=9$} \\
\hline \multicolumn{2}{|l|}{ Gender } \\
\hline Female & 9 \\
\hline Mean age, years (range) & $31(21-44)$ \\
\hline \multicolumn{2}{|c|}{$\begin{array}{l}\text { First in family to undertake } \\
\text { further studies }\end{array}$} \\
\hline Yes & 3 \\
\hline No & 6 \\
\hline \multicolumn{2}{|l|}{ Country of Birth } \\
\hline Australia & 7 \\
\hline Asia & 2 \\
\hline \multicolumn{2}{|l|}{ Language spoken at home } \\
\hline English & 8 \\
\hline Hindi & 1 \\
\hline \multicolumn{2}{|l|}{ Years using an iPad } \\
\hline 1 & 3 \\
\hline 2 & 1 \\
\hline 3 & 5 \\
\hline \multicolumn{2}{|c|}{ Previous ownership of an iPad } \\
\hline Yes & 4 \\
\hline No & 5 \\
\hline
\end{tabular}

\section{Procedure}

Interviews were either conducted in the university library meeting rooms or over the phone ( $\mathrm{n}=2$ ). Data collection continued until data saturation was reached. Interview data were transcribed verbatim using a professional transcription service; the confidentiality of the participants was maintained by the use of a re-identifiable code to replace participant names.

\section{Data analysis}

Thematic analysis was coupled with unpacking the interpretative relationship of and between the transcripts, in order to understand the content and complexity of the meanings. The steps involved were described by Smith and Osborn (2008) and required the documentation of initial notes and emergent themes. The emergent themes were then given a superordinate theme title, and finally a master table of superordinate and emergent themes was developed using keywords. The line and page number were included to link the themes to the transcript. This graphic representation on a Microsoft Excel spreadsheet allowed for the observation of abstraction, polarisation and contradictions. The dependability of this research was enhanced through the consistency of the interview approach by using a participant interview schedule. Confirmability was established by developing a transparent audit trail which allowed the research team to guarantee the trustworthiness of the data.

\section{Findings}

The data analysis revealed one overarching theme that captured the essence of the experience for all nine participants: Unleashing the iPad's potential for nursing students. The overarching theme encompasses the concept that the iPad's potential for students was not realised and participants' described the importance of metaphorically 'unleashing' this potential. Although the University provided the iPad to students free of charge, the participants acknowledged that they did not realise all the capabilities of the iPad in support of their studies. This theme is encapsulated by the four superordinate themes, listed in Table 2, which tell the participant's journey; the iPad encounter, adapting to the Apple device, connecting technology to learning, and unrealised capabilities. Each of the four super-ordinate themes are then supported by two to three emergent themes. All participant quotes use pseudonyms to maintain confidentiality. 


\begin{tabular}{ll}
\multicolumn{1}{c}{ Overarching theme } \\
\hline Superordinate themes & Emergent themes \\
1. iPad encounter & 1.1 Supporting their studies \\
& 1.2 Necessity versus affordability \\
& 1.3 Note taking ability \\
& 2.1 Identified limitations \\
2. Adapting to the Apple device & 2.2 Assignment preparation: PC versus iPad ${ }^{\circledR}$ \\
& 2.3 Design features and lifestyle \\
& 3.1 Students' learning styles within a blended \\
3. Connecting technology to learning & learning environment \\
& 3.2 Tutors' use of the iPad ${ }^{\circledR}$ \\
& 3.3 Technological deficits \\
& 4.1 The missed opportunity \\
4. Unrealised capabilities & 4.2 Providing a foundation of support \\
\hline
\end{tabular}

\section{Theme 1: The iPad encounter}

\subsection{Supporting their studies}

This first theme identified how the participants utilised the iPad to support their studies. Cath explained "it is great, good in class or if you need to quickly look something up if you are unsure about a word or something like that it is really good" (P8). Ann was a new user to the iPad and revealed: "at first I had no clue how to use an iPad I had never really touched one, but once I started getting used to it, it became really beneficial in the classroom (P3). Jo described the use of the iPad in tutorials: "in class you can just open up the article, quickly skim through it again so that you pick up the main points and that has been a brilliant thing” (P2). Val mentioned the benefit of the iPad in group work: "if the teacher asks to do the group work and research, this [the iPad] is very helpful, if we don't have that [the iPad] we don't know what to do (P5). Ann mentioned: "I can access anything I need to in class without having to carry around a huge bulky laptop, it also saves on things like printing as a poor student that is important" (P3). The reference to a "poor student" highlighted the financial advantage of the iPad. Beth used the iPad to practice for the assessment: "the videos have been really, really good so while I am practicing for the OSCA [Objective Structured Clinical Assessment] I will have a look at the YouTube videos (P9). In contrast, Cath's experience of using the iPad was: "I find it a bit of a distraction" and went on to say "probably one of the main things I use it for is to read the news" (P8). Considering the iPad was chosen because of the range of educational apps, the participants used minimal apps in support of their studies. Jess used "Blackboard" and also "Evernote" (P7). However, Ann did not use any apps: "none really relevant to university other than the YouTube app" (P3).

\subsection{Necessity versus affordability}

The participants found the iPad beneficial for their studies, however when asked if they would have purchased their own iPad to support their studies, eight of the participants said no, mainly for financial reasons. Ann stated: "I can see it is beneficial, but to be honest I would never have bought one on my own without actually receiving it" (P3). Similarly, Eve stated: "I was limited again to be able to afford another electronic device so to be given one from the university has helped me in that situation" (P6). Eve's reference to "another electronic device" revealed that she initially purchased an alternative device to the iPad. 


\subsection{Note taking ability}

The majority of participants did not use the iPad to document or take notes. All nine participants hand wrote their notes and only two typed notes on the iPad in addition to handwriting. This preference to hand write notes was related to age, technological skills and learning styles. Lyn indicated: "I feel that is how I learn, I feel I am that sort of learner, I am not like the young kids [whispers 35 years old] I am not 20 just out of high school and is used to all this technology, I'm old school, I like to write it down on paper" (P1). Ann mentioned her slow typing skills as a barrier to digital note taking: "I am not a very fast typist so I prefer just to scribble as I hear it" (P3). Jess used both methods: "sometimes I use the iPad, the Evernote app ...important notes then I write it on my notebook (P7). Jo used digital note taking in clinical classes: "in clinical classes because you don't really take in pens and paper, you have your iPad and you can quickly type in information that the teacher says (P2). Jo was aware that there were apps to annotate but was unsure where to find the ones that have Word processing capabilities for the iPad: "probably more handwriting ...I mean I don't know whether it is because I haven't looked properly but I don't find that the iPad itself has enough, umm like Word ...Word apps,” (P2).

\section{Theme 2: Adapting to the Apple device}

\subsection{Identified limitations}

The iPad is an Apple product which Sue commented was not compatible with the learning materials in the undergraduate degree: "you are providing us with an iPad which is an Apple based product and that is what we are meant to be using and then you tell us we have to download and use Chrome or something and Apple doesn't like Chrome anyway so it all just becomes a big mess" (P4). Eve commented: "being an Apple device you are restricted sometimes with the kind of files you often open" (P6) and Jo mentioned: "some of the quizzes we have to do we cannot use the iPad" (P2). When utilising the iPad for her studies Cath mentioned: "iPads you cannot back anything up really, there is no USB [Universal Serial Bus] to easily save stuff and I so I just think the laptop is better, better keyboard to type and everything” (P8).

\subsection{Assignment preparation: PC (Personal Computer) versus iPad}

All nine participants did not use the iPad for assignment preparation as they identified several limitations. Val's reason for using the laptop was: "if I do my assignment I prefer to do with my laptop ...I can copy and paste and I can do a lot of things on there ...I prefer laptop ...old generation, that is what I am” (P5). The "copy and paste” mode can be performed on an iPad. This lack of knowledge on how to use the iPad confirms the overarching theme and the need to 'unleash the iPad's potential for nursing students'. Jess revealed that her preference to use a laptop for assignments was due to familiarity and relative comfort with this device. "I would still go for the laptops because I am comfortable with them, I don't like feel comfy with the iPad as much as the laptop ...I like the real keyboard” (P7).

\subsection{Lifestyle and design features}

Although participants preferred the laptop for assignment preparation, the iPad did make an impression on participants in the area of lifestyle and design features. Jo noted: "I use the iPad all the time because it is transportable; it is so easy you can take it anywhere" (P2). Beth further added: "I mean it is more portable and definitely more convenient than using a laptop" (P9). Eve commented: "it is lightweight; it is small" (P6). Val also makes the comparison between the iPad and laptop: "it is quite easy to hold in bed instead of laptop in front of your face" (P5). Five of the participants agreed the iPad was their preference of device to support their studies due to the design features, however a PC was the technology of choice for assignment preparation. 


\section{Theme 3: Connecting technology to learning}

\subsection{Students' learning styles within a blended learning environment}

Since 2012, the undergraduate nursing curriculum had a blended learning strategy, incorporating the iPad, which included a mix of face-to-face learning, online lectures and learning activities, lectures and workplace experience. The majority of participants stated enjoying the blended learning approach in comparison to previous styles of learning involving face-to-face lectures. Lyn commented: "I think the access that you can watch things over and over again, I think back in the day you used to have lectures and you know you would only get one shot at it, but now I can, if I need to, access and watch something over" (P1). Val enjoyed blended learning: "English is my second language I prefer the online as well as in the class" (P5). Lyn described the disadvantages to an online only elective: "I sort of missed coming to uni and doing a tute and clarifying things" (P1). Time was an important factor for Ann's learning: "the thing I like about the blended learning is I have the time to do the lectures when I have the time so it makes it a lot easier in the sense of time management" (P3). Beth agreed: "if it was all face-to-face and I had to come in five days a week I wouldn't have done the degree” (P9). Overall, the 'blend' of learning was well received by the participants and was conducive to their learning styles.

\subsection{Tutors' use of the iPad}

The majority of participants had never observed the tutor's use an iPad. Cath stated: “no, I can't say I have ever seen a tutor use the iPad or even direct it or even mention it in class" (P8). Only three participants stated they had seen or been directed to use the iPad by the tutor in the classroom: "my tutor will have her iPad out and so she will walk around and she'll go through it so she is seeing what we are seeing which is good so we are on the same track" (P2). Considering a large percentage of the tutors are casual and hence do not receive an iPad, this may be one of the reasons the iPad was not used by tutors. One participant expressed concern that the iPad would replace the teacher: "I prefer communication between the teacher and student rather than having the iPad as the teacher so to speak” (P2).

\subsection{Technological deficits}

This theme emphasised how the participants acquired the technological skills to use the Apple iPad device. Ann sought family support: "I kind of got my nephew to show me how to use it because he uses the iPad ...how to download stuff and how to browse and everything because I had no idea what to do with it" (P3). Ann's comment "I had no idea" emphasised how perplexing it was to be given a device with no instructions. Furthermore, Ann revealed: "I consider myself quite tech savvy when it comes to computers and phones and all that but I don't use Apple products ...I thought how the hell do I use this" (P3). Cath used a variety of resources: "I went to the Apple store to ask them a few things and otherwise I have just Googled stuff or I have picked my boyfriend's brain” (P8). Cath also sought assistance from other students: "trying to get documents open in Word can be a bit of a nightmare but talking to other students ...they have sort of helped me ...maybe I am just an incompetent user" (P8). This theme highlighted the frustration of the students and linked into the overarching them that there is a need to unleash the iPad's potential as well as providing training on how to use technological devices.

\section{Theme 4: Unrealised capabilities}

\subsection{The missed opportunity}

Without a foundation of support and training, the iPad could not be used to its potential and minimal instruction was given to the participants on how to use the iPad for their studies. Lyn said: "it was pretty hectic on the iPad collection day ...there were people there to help us to set it up but 
then once that was done most people just walked away ...I was sitting there and I was just listening to everyone and I was just figuring it out myself” (P1). Jess further added that she would have liked assistance on its use initially: "I also think that if someone could tell me about the things that are available on the iPad it could be much easier because I found the MyC3 and the Blackboard much later" (P7). Jess's reference to "much later" emphasised the time that had elapsed between receiving the iPad and then finding out about the available apps. Similarly, Eve mentioned: "I do not know how to use OneNote yet and OneNote would be helpful to use on there because I could write and add text to the documents that I am already getting from the tutorial” (P6). Beth was asked if she used the Blackboard app which is one of the main learning platforms and she said: “no, I don't know how to use Blackboard, I wouldn't have a clue they showed us how to turn it on and put your password in" (P9). Lyn expressed she would have appreciated help with the iPad beyond the basic set up. Lyn remarked: "even though I am a little bit tech savvy I would have still liked someone to go through the process...these are the apps you need and so forth” (P1).

\subsection{Providing a foundation of support}

Having missed the opportunity to instruct the participants on how to use the iPad to support their nursing studies, it was evident that the participants consequently found it difficult to unleash the iPad's potential. Ann believed: "I think it would be really, really helpful if they would put on workshops for students on how to use the iPad ... at the start of a semester" (P3). Eve similarly felt she would benefit from an iPad workshop: "I think it would be beneficial again to have a workshop or someone to facilitate how to use apps that you download like OneNote or Notability or even using vUWS [virtual UWS] ...because it is software that would benefit you in your studies if you knew how to use it properly" (P6). Jo suggested: "I think things like the you know Blackboard and the OWA app really should be spoken about ...sometimes they can come pre-loaded ...so that they are there ready to go once the student starts" (P2). Sue further commented on apps: "the apps are just a plethora of things and unless you know what you are looking for, you can spend absolutely hours and days trying to find things" (P4). A salient comment was made by Jo as to the purpose of the iPad: "...how much do you need to use it, do I have to use it every day, do I have to bring it to all my classes, what is the purpose of having this iPad when I don't know how to use it properly" (P2). The lack of guidance on the basic use and "purpose of having the iPad" highlighted the uncertainty for some surrounding the necessity of the iPad to support their studies.

\section{Discussion}

This research supported current literature, in that students appreciated the convenience of accessing the Internet and learning material in the classroom (Alyahya \& Gall, 2012; Hahn \& Bussell, 2012). It revealed that the majority of participants preferred hand writing notes over digital note taking. Like Kinash et al. (2011) students felt it was "more beneficial to take pen and paper notes” (p. 7). In contrast, Alyahya and Gall (2012) highlighted the iPad as the main device for note taking and accordingly Mang and Wardley (2012) outlined the benefits of digital note taking such as a reduction in cost and time of printing notes, carrying paper, and the advantage of instant access to documents. Despite the mixed views, this research challenges the literature that suggests the millennial generation, born between 1977 and 1995, have advanced skills with using digital technology. Five of the nine participants were Millennials, an era rich with technology and digital media, (McMahon \& Pospisil, 2005), and yet they did not use the iPad for note taking and required assistance with its use.

Like Hahn and Bussell (2012), our participants identified compatibility issues between the software and device which limited access to learning resources. Participants noted a key limitation of the iPad was the absence of a USB which was raised in other studies (Culén \& Gasparini, 2011; Eichenlaub et al., 2011; Kinash et al., 2011). Likewise, the keyboard size was another limitation 
and this finding is supported by Rossing et al. (2012). To address this issue, students in the study by Eichenlaub et al. (2011) emphasised the significance of hardware add-ons such as a wireless keyboard, docking station, conductive stylus or apps that improved note taking without the use of a keyboard. Rossing et al (2012) felt the device was initially confusing due to its unfamiliarity; creating frustration and increasing operation time. Some of our participants had similar issues with the use of apps and the software, despite some already owning an iPad. Despite these limitations, our participants still favoured the portability and convenience of the iPad in contrast to the size of a laptop. In support of Klapdor and Uys (2013) the PC or laptop was still the preferred device for assignment preparation.

The iPad allowed the participants to access learning material at their convenience, underscoring the flexibility of the blended learning strategy which may have the benefit of increasing student engagement (Van Doorn \& Van Doorn, 2014). Access and eligibility however for staff was limited to permanent academic staff; casual or fixed term staff did not receive an iPad (UWS, 2015). According to the National Tertiary Education Union (2013) "over 50\% of teaching across the university sector is now done by casuals" (p. 3). This represents a large percentage of teaching staff who would not qualify for an iPad and may be a factor hindering the success of the blended learning strategy using the iPad.

Finally, this research has uncovered the need for preparation and training of students when commencing an iPad initiative. The importance of structured iPad training sessions and informal activities in preparation for an iPad initiative cannot be underestimated (Cavanaugh, Hargis, Munns \& Kamali, 2013). Cordier, McAuliffe, Wilson, Totino, Dender, Smith and Stephens. (2015) advised the benefits of extensive training and support for students and staff prior to the implementation of learning technology. We strongly support Wakefield and Smith (2012) and Nicolle and Lou's (2008) sentiments in that there must be commitment and accountability on universities when integrating technology for learning to ensure that both students and staff are provided with not only the resources, but the support and skill development in the use of technology. Evidence-based ways to achieve this in an appropriate, feasible and effective manner are needed.

\section{Recommendations for future research}

Future research could be widened to focus on tutors, thereby gaining a different perspective as their perceptions and experiences would add valuable insight to these findings and uncover the barriers for tutors. Additionally, an action research project based on educating students and staff how to integrate the iPad into teaching would add significantly to the evidence base for m-learning. Future research could identify if the design limitations identified within this research have been resolved with future generations of iPads released and if other portable devices may be more suitable for student use.

\section{Limitations}

Using IPA, this research was reliant on the participants involved, their ability to self-disclose and express their thoughts effectively. Two participants were from a Non-English Speaking Background and had difficulty understanding some questions, further one of these interviews was conducted via the telephone. Telephone interviews are a convenient method, however are "often less effective" (Polit \& Beck, 2006, p. 241). The voluntary nature of the recruitment strategy resulted in an allfemale sample; this was not totally unexpected as the majority of nursing undergraduate students were female. Whether having a number of male participants would have altered the findings remains open to conjecture, however as males and females are reported to have different learning styles (Wehrwein, Lujan \& DiCarlo, 2007) our findings cannot be generalised. Despite this, there was a wide age range of participants from 21 to 44 years, providing insight from two generations. 


\section{Conclusion}

Considering the iPad has only been on the market for seven years, this research base is still in its infancy and technology will continue to advance rapidly challenging traditional learning styles and teaching philosophy. The demand for learning anywhere and anytime has forced universities to adapt their learning frameworks. The implementation of the iPad initiative, combined with the blended learning strategy, has provided an opportunity for students to learn ubiquitously with a mobile learning device. This research has given voice to nursing students who tell us that the iPad is a useful device to support tertiary studies, but much support is needed to avoid the potential pitfalls in any wholesale rollout approach using technology for learning.

\section{Acknowledgements and disclosures}

We would like to acknowledge the time and input of the participants. No financial assistance was required for this project. 


\section{References}

Alyahya, S., \& Gall, J. E. (2012). iPads in education: A qualitative study of students' attitudes and experiences. In T. Amiel \& B. Wilson (Eds.), Proceedings of EdMedia: World conference on educational media and technology 2012 (pp. 1266-1271). Colorado, USA: Association for the Advancement of Computing in Education (AACE).

Bansavich, J. C., \& Yoshioka, K. (2011, October). The iPad: Implications for higher education. Paper presented at the 2011 EDUCAUSE annual conference. University of San Francisco, USA.

Brown, J., \& McCrorie, P. (2015). The iPad: Tablet technology to support nursing and midwifery student learning: An evaluation in practice. Computers Informatics Nursing, 33, 93-98. doi: 10.1097/CIN.0000000000000131

Cavanaugh, C., Hargis, J., Munns, S., \& Kamali, T. (2013). iCelebrate teaching and learning: Sharing the iPad experience. Journal of Teaching and Learning with Technology, 1(2), 1-12

Cordier, R., McAuliffe, T., Wilson, N. J., Totino, R., Dender, A., Smith, C., \& Stephens, M. (2015). The appropriateness and feasibility of an online e-Portfolio for assessment of undergraduate allied health students. Australian Occupational Therapy Journal. Advance online publication. doi: 10.1111/1440-1630.12226

Culén, A. L., \& Gasparini, A. (2011). iPad: A new classroom technology? A report from two pilot studies. Paper presented at the INFuture 2011: Information Sciences and e-Society, Zagreb, Croatia.

Diemer, T. T., Fernandez, E., \& Streepey, J. W. (2012). Student perceptions of classroom engagement and learning using iPads. Journal of Teaching and Learning with Technology, 1(2), 13-25.

Eichenlaub, N., Gabel, L., Jakubek, D., McCarthy, G., \& Wang, W. (2011). Project iPad: Investigating tablet integration in learning and libraries at Ryerson University. Computers in Libraries, 31(7), 17-21.

Gillis, A., \& Jackson, W. (2002). Research for nurses: Methods and interpretation. Philadelphia, PA: F. A. Davis Company.

Hahn, J., \& Bussell, H. (2012). Curricular use of the iPad 2 by a first-year undergraduate learning community. Library Technology Reports, 48(8), 42-47.

Kinash, S., Brand, J., Mathew, T., \& Kordyban, R. (2011). Uncoupling mobility and learning: When one does not guarantee the other. In R. Kwan, C. McNaught, P. Tsang, F. L. Wang \& K. C. Li (Eds.), Enhancing learning through technology. Education unplugged: Mobile technologies and Web 2.0 (pp. 342-350). Berlin: Springer.

Klapdor, T., \& Uys, P. (2013). Mobile learning at Charles Sturt University: Lessons learned from university-wide iPad trials in 2012. Paper presented at the 30th Ascilite Conference, Macquarie University, Sydney, Australia.

Mang, C. F., \& Wardley, L. J. (2012). Effective adoption of tablets in post-secondary education: Recommendations based on a trial of iPads in university classes. Journal of Information Technology Education: Innovations in Practice, 11, 301-317.

McMahon, M., \& Pospisil, R. (2005). Laptops for a digital lifestyle: Millennial students and wireless mobile technologies. In H. Goss (Ed.), Balance, Fidelity, Mobility: Proceedings of the 22nd ASCILITE Conference (pp. 421-431). Brisbane, Queensland Queensland University of Technology.

National Tertiary Education Union. (2013). News. Sydney, NSW: National Tertiary Education Union.

Nguyen, L., Barton, S. M., \& Nguyen, L. T. (2015). iPads in higher education-Hype and hope. British Journal of Educational Technology, 46, 190-203. doi: 10.1111/bjet.12137

Nicolle, P. S., \& Lou, Y. (2008). Technology adoption into teaching and learning by mainstream university faculty: A mixed methodology study revealing the "how, when, why, and why not". Journal of Educational Computing Research, 39, 235-265. doi: 10.2190/EC.39.3.c

Peng, H., Su, Y.J., Chou, C.,\& Tsai, C. (2009). Ubiquitous knowledge construction: Mobile learning re-defined and a conceptual framework. Innovations in Education and Teaching International, 46, 171-183. doi: 10.1080/14703290902843828

Polit, D. F., \& Beck, C. T. (2006). Essentials of nursing research. Methods, appraisal, and utilisation (6th ed.). Philadelphia: Lippincott Williams \& Wilkins.

Rossing, J. P., Miller, W. M., Cecil, A. K., \& Stamper, S. E. (2012). iLearning: The future of higher education? Student perceptions on learning with mobile tablets. Journal of the Scholarship of Teaching \& Learning, 12(2), 1-26.

Sloan, R. H. (2012). Using an e-Textbook and iPad: Results of a pilot program. Journal of Educational Technology Systems, 41, 87-104. 
Smith, J., \& Osborn, M. (2008). Interpretative phenomenological analysis. In J. Smith (Ed.), Qualitative psychology: A practical guide to methods (2nd ed., pp. 53-80). London: Sage.

Smith, M., Kukulska-Hulme, A., \& Page, A. (2012). Educational use cases from a shared exploration of e-books and iPads. In T.T. Goh (Ed.), E-books and e-readers for e-learning (pp. 25-53). Wellington, New Zealand: Victoria Business School, Victoria University of Wellington.

Traxler, J. (2010). Will student devices deliver innovation, inclusion, and transformation? Journal of the Research Center for Educational Technology, 6(1), 3-15.

University of Western Sydney. (2015). Strategies for engagement. Retrieved from http://www.westernsydney.edu.au/qilt/qilt/designing_for_learning/strategies_for_engagement

University of Western Sydney. (2015a). UWS deploys iPads to support IT-enhanced learning. Retrieved from http://www.uws.edu.au/newscentre/news_centre/story_archive/december_2012/uws_deploys_ipads_to_suppor t_it-enhanced_learning

University of Western Sydney. (2015b). iPad questions and answers. Retrieved from http://www.westernsydney.edu.au/learning_teaching/learning_and_teaching/ipad_initiative/ipad_faq

Van Doorn, J. R., \& Van Doorn, J. D. (2014). The quest for knowledge transfer efficacy: Blended teaching, online and in-class, with consideration of learning typologies for non-traditional and traditional students. Frontiers in Psychology, 5(324), 1-14. doi: 10.3389/fpsyg.2014.00324

Wakefield, J., \& Smith, D. (2012). From socrates to satellites: iPad learning in an undergraduate course. Creative Education, 3(5), 643-648. doi: 10.4236/ce.2012.35094

Wehrwein, E. A., Lujan, H. L. \& DiCarlo, S.E. (2007). Gender differences in learning style preferences amoung undergraduate physiology students. Advances in Physiology Education, 31(2),153-157. doi: 10.1152/advan.00060.2006

\section{The authors may be contacted via}

c.walker@westernsydney.edu.auUnder the Radar: 